\title{
Partial Hydrogenation of Unsaturated Carbonyl Compounds: Towards Ligand-Directed Heterogeneous Catalysis
}

\author{
Swetlana Schauermann \\ Institute of Physical Chemistry, Christian-Albrechts-University Kiel, \\ Max-Eyth-Strasse 2, 24118 Kiel, Germany.
}

\begin{abstract}
In this perspective, we report on the recent progress in atomistic-level understanding of selective partial hydrogenation of $\alpha, \beta$-unsaturated carbonyl compounds, particularly acrolein, towards unsaturated alcohols over model single crystalline and nanostructured Pd catalysts. This reaction was observed to proceed with nearly $100 \%$ selectivity over $\mathrm{Pd}(111)$ but not over supported Pd nanoparticles. The origin of the high selectivity was related to formation of a dense overlayer of oxopropyl surface species occurring at the early reaction stages via partial hydrogenation of the $\mathrm{C}=\mathrm{C}$ bond in acrolein with only one $\mathrm{H}$ atom. This oxopropyl overlayer strongly modifies the adsorption and reactive properties of $\mathrm{Pd}(111)$ turning it $100 \%$ selective towards $\mathrm{C}=\mathrm{O}$ bond hydrogenation. The underlying reaction mechanism represents a particular case of ligand-directed heterogeneous catalysis, in which the surface adsorbates do not directly participate in the catalytic process as the reaction intermediates but strongly affect the elementary reaction steps via specific adsorbate-adsorbate interactions.
\end{abstract}



Figure for the Table of Content 


\section{Introduction}

One of the major challenges in the modern heterogeneous catalysis research is a control over the selectivity of a catalytic process, allowing to preferably produce one of many other thermodynamically feasible products. A selective catalyst enables a more economical use of the available feedstocks and energy and allows to avoid the subsequent cost and energy expensive separation steps.

The selectivity of a multi-path surface reaction depends on the subtle differences in the potential-energy barriers of individual reaction pathways, which is difficult to control. Indeed, a catalytic surface showing high activity for the desired reaction pathway might also greatly accelerate the unwanted reaction paths and the final selectivity will mainly depend on the small differences in the corresponding activation barriers. A strategy to overcome this problem, is to introduce a specific selective interaction between a reactant and a catalytically active site, which can govern the chemical transformations only into the desired direction. Such highly specific reactant/active site interactions are ubiquitous in enzymes ${ }^{1}$ and have been successfully implemented into homogeneous catalysts through e.g. modification of an active site with organic ligands. ${ }^{2-3}$ Currently, a similar approach is being developed for surface catalyzed reactions by combining two functionalities inherent to heterogeneous and homogeneous catalysis: high activity of a catalytic surface and a specific interaction between the reactant and the active site, which directs the chemical transformations towards the desired reaction route. ${ }^{4-8}$ One of the most successful strategies to introduce this specific interaction is the modification of a catalytic surface with ligand-like adsorbates, e.g. organic adsorbates or covalently bonded functional groups, allowing for a selective promotion of the desired reaction path. Recently, such surface modification has gathered significant interest for the development of "ligand-induced" or "ligand-directed" heterogeneous catalysis for a variety of reactions. Some prominent examples are related to enantioselective heterogeneous catalysis on chirally-modified surfaces or partial selective hydrogenation of multi-unsaturated hydrocarbon compounds. ${ }^{5-6,9-11}$ In such systems, the most beneficial properties of heterogeneous and homogeneous catalysis are combined in a synergistic way with the surface being responsible for the lowering of the activation barriers and the ligand/reactant intermolecular interaction accounting for a selective promotion of a desired reaction pathway.

Despite the impressive developments in this field, the mechanistic details of the underlying surface processes and the reaction mechanisms responsible for ligand-directed catalysis remain only purely understood for the most of the known catalytic systems. In this perspective, we provide an example of heterogeneously catalyzed reaction, for which the mechanisms of the ligandinduced catalysis were rationalized at the microscopic level. Specifically, we present an atomisticlevel study on selectivity of acrolein partial hydrogenation, which was investigated over two model catalysts - single crystalline $\mathrm{Pd}(111)$ and a nanostructured model catalyst containing supported Pd NPs that were epitaxtially grown on a well-ordered $\mathrm{Fe}_{3} \mathrm{O}_{4} / \mathrm{Pt}(111)$ support. ${ }^{12-16} \mathrm{On} \mathrm{Pd}(111)$, partial hydrogenation of acrolein was very unexpectedly observed to occur with $100 \%$ selectivity towards the desired yet very difficult hydrogenation of the carbonyl group leading to unsaturated alcohol 
(propenol) formation. We show that this process occurs not on pristine $\operatorname{Pd}(111)$ but at the surface, whose structure is strongly modified by the presence of a densely-packed layer of ligand-like species, particularly oxopropyl groups, which builds up during the early stages of the reaction via hydrogenation of the $\mathrm{C}=\mathrm{C}$ bond of acrolein only with one hydrogen atom. This oxopropyl layer was found to be responsible for exceptionally high selectivity towards the desired reaction route selective hydrogenation of the carbonyl group, occurring on the ligand-modified $\operatorname{Pd}(111)$. By performing in operando infrared reflection-absorption spectroscopy (IRAS) and molecular beam experiments under well-defined ultra-high vacuum (UHV) conditions, we identified the chemical composition of the reaction intermediates and the ligand spectator species formed on the surface during the reaction. Further, we were able to observe a strong correlation between the formation rate of molecular propenol in the gas phase and the concentration of the reaction intermediate on the surface. The related mechanisms are expected to be relevant for a broad class of ligand-directed surface reactions and provide important atomistic-level insights for further rational development of new catalytic materials.

\section{Selectivity in acrolein partial hydrogenaiton over Pd(111) vs. supported Pd nanoparticles}

Partial hydrogenation of $\alpha, \beta$-unsaturated ketones and aldehydes to unsaturated alcohols is of pivotal importance for pharmaceutical applications and fine chemical synthesis. ${ }^{7}, 17$ The undesired competing reaction $-\mathrm{C}=\mathrm{C}$ bond hydrogenation - leading to formation of saturated ketones and aldehydes is, however, a thermodynamically more favored process with the unwanted products being by about $30 \mathrm{~kJ} \cdot \mathrm{mol}^{-1}$ more stable than the alcohols. Hence, the target reaction hydrogenation of the carbonyl group - requires control over the kinetics of the competing reaction pathways by appropriate catalysts. Previously, this class of reactions was widely investigated in catalytic studies on powdered materials as well as in model studies on single crystals, particularly over Pt group metals. ${ }^{7}{ }^{17-19}$ In these studies, the $\mathrm{C}=\mathrm{C}$ bond hydrogenation pathway was observed to be strongly favored with the selectivity close to $100 \%$. A common strategy to avoid the unwanted $\mathrm{C}=\mathrm{C}$ bond hydrogenation relies on steric protection of this group, e.g. by using prenal instead of acrolein. ${ }^{20-21}$ Alternatively, supports based on reducible oxide, such as $\mathrm{TiO}_{2}$ were employed to introduce Lewis-acid sites that were envisaged to activate the carbonyl group. ${ }^{22-24}$

Despite these developments, the fundamental challenge of partial hydrogenation of a carbonyl group in $\alpha, \beta$-unsaturated aldehydes and ketones still persists, particularly for the small molecules such as e.g. acrolein, which are not sterically protected on the $\mathrm{C}=\mathrm{C}$ double bond.

To obtain more fundamental-level insights into partial selective hydrogenation of this class of multi-unsaturated hydrocarbon compounds, we performed mechanistic and kinetic studies on acrolein hydrogenation over different types of Pd model catalysts under UHV conditions following a rigorous surface science approach. ${ }^{12-16,25}$ The reaction scheme shown in Figure 1 illustrates two competing reaction pathways of partial selective hydrogenation of acrolein either to the desired product propenol or to unwanted propanal. These processes were studied on two types of model surfaces: (i) a single crystal $\mathrm{Pd}(111)$ and (ii) Pd NPs prepared in-situ under UHV supported on a $\mathrm{Fe}_{3} \mathrm{O}_{4} / \mathrm{Pt}(111)$ oxide film. Experimentally, these catalysts were exposed to the reactants - acrolein and $\mathrm{H}_{2}$ - under isothermal conditions in a highly controlled way by using molecular beam 
techniques. At the same time, the product formation rate was monitored in the gas phase by quadrupole mass spectrometry (QMS) and the evolution of the surface species - the reaction intermediates and the spectator species - formed under the reaction conditions was followed by in operando IRAS.

Figure 2 displays the formation rates of two possible products resulting from competing hydrogenation reactions of either the carbonyl group to form propenol (blue traces, Fig. $2 \mathrm{~b}$ and $2 \mathrm{~d}$ ) or the $\mathrm{C}=\mathrm{C}$ double bond leading to propanal formation (black traces, Fig. $2 \mathrm{c}$ and $2 \mathrm{a}$ ) measured on supported Pd nanoparticles (left side, the STM image is shown in Fig. 2e) and on Pd(111) (right side) that were obtained at different surface temperatures. In these experiments, the model catalysts were continuously exposed to a $\mathrm{H}_{2}$ molecular beam prior to acrolein exposure to saturate $\mathrm{Pd}$ with hydrogen. At the time moment indicated as zero, a series of acrolein pulses was applied and the reaction rates of the competing pathways were recorded in the gas phase. On the Pd nanoparticles, only minor amounts of undesired product propanal were formed during the few pulses at the beginning of acrolein exposure with the formation rate quickly dropping to zero level (Fig. 2c), while no formation of propenol was observed (Fig. 2d). This finding agrees well with the earlier studies performed under ambient pressure conditions on powdered Pd catalysts. ${ }^{17}$, 19 In sharp contrast to Pd nanoparticles, very high catalytic activity and $100 \%$ selectivity towards propenol formation was observed on $\operatorname{Pd}(111)$ (Fig. 2a and 2b). The rate of this desired reaction pathway shows a strong temperature dependence with a maximum lying between 250 and $270 \mathrm{~K}$.

3. Spectroscopic identification of the surface species formed under the reaction conditions on $\operatorname{Pd}(111)$.

Having detected an outstanding catalytic performance of $\operatorname{Pd}(111)$, we scrutinized the chemical composition of this active surface under the operational conditions by performing time resolved IRAS measurements. In these experiment, the surface was continuously exposed first to $\mathrm{H}_{2}$ followed by simultaneous exposure to independent acrolein and hydrogen beams. The formation rates of both reaction products in the gas phase recorded in this experiment at $270 \mathrm{~K}$ are displayed in Figure 3a. The propanal formation rate (black trace) remaines always zero. The time evolution of the propenol formation rate (blue trace) can be tentatively divided into three regimes: (I) an induction period, in which both reactants are accumulated on the catalyst's surface but no products desorb into the gas phase; (II) the period of the highest propenol formation rate and (III) slow deactivation of the catalyst resulting in declining propenol production. Figure $3 b$ shows the chemical composition of the species formed on the surface during the reaction: the spectra $(1-4)$ are related to the four reactivity regimes indicated in Figure $3 \mathrm{a}$ on the time axis: the spectrum (1) comprises the induction period (I) and the period related to growing reactivity; the spectra (2) and (3) are related to the period of the highest reactivity (II); the spectrum (4) shows the chemical composition of the adsorbates during deactivation. The last spectrum on the bottom was recorded after a prolonged $\mathrm{H}_{2}$ and acrolein exposure and corresponds to a completely inactive surface. In all spectra, the following spectral regions can be distinguished: the $\mathrm{CH}_{\mathrm{x}}$ stretching vibrations 
(3200-2700 $\left.\mathrm{cm}^{-1}\right) ; \mathrm{C}=\mathrm{O}$ and $\mathrm{C}=\mathrm{C}$ stretching vibrations $\left(1850-1550 \mathrm{~cm}^{-1}\right) ; \mathrm{CH}_{\mathrm{x}}$ deformation, $\mathrm{C}-\mathrm{O}$ and $\mathrm{C}-\mathrm{C}$ stretching vibrations $\left(\leq 1500 \mathrm{~cm}^{-1}\right)$.

The uppermost spectrum (top of the Figures 3b, gray trace) is a reference for a molecular non-reactive state of acrolein, which was obtained on $\mathrm{Pd}(111)$ at $100 \mathrm{~K}$ at the surface coverage close to a full monolayer. The most prominent band at $1663 \mathrm{~cm}^{-1}$ in this spectrum can be assigned to the stretching vibration of the $\mathrm{C}=\mathrm{O}$ double bond, which is conjugated to the $\mathrm{C}=\mathrm{C}$ group. The bands in the range $1430-1400 \mathrm{~cm}^{-1}$ are related to a scissor deformation of the methylene $\left(\mathrm{CH}_{2}\right)$ group. ${ }^{26-29}$

The spectrum (1) in Figure 3b comprising the induction period and the period of increasing activity is clearly different from the spectrum of molecular acrolein. Specifically, two new prominent bands appear at $1755 \mathrm{~cm}^{-1}$ and at $1120 \mathrm{~cm}^{-1}$. The band at $1755 \mathrm{~cm}^{-1}$, which is shifted by $92 \mathrm{~cm}^{-1}$ from the vibrational frequency of carbonyl group in acrolein, is characteristic for the $\mathrm{C}=\mathrm{O}$ stretching vibration in saturated ketones and aldehydes. ${ }^{30-31}$ The appearance of this band suggest that a new surface species is formed under the reaction conditions containing a $\mathrm{C}=\mathrm{O}$ bond, which is not conjugated to the $\mathrm{C}=\mathrm{C}$ bond. This species can be identified as an oxopropyl surface species $\left(\mathrm{CH}_{3}-\mathrm{CH}-\mathrm{CH}=\mathrm{O}\right.$ or $\left.\mathrm{CH}_{2}-\mathrm{CH}_{2}-\mathrm{CH}=\mathrm{O}\right)$, which results from the first half-hydrogenation step of the $\mathrm{C}=\mathrm{C}$ double bond in acrolein with a single $\mathrm{H}$ atom (the possible structures is shown in Figure $3 \mathrm{~b}$ in red). It is important to point out that the intensity of the vibration at $1755 \mathrm{~cm}^{-1}$ increases in the course of the reaction and later saturates at a constant level, despite the fact that the propenol formation rate in the gas phase continuously diminishes to zero during that time. This observation implies that the related adsorbates - oxopropyl species - are not directly involved into the reaction of propenol formation as the reaction intermediate but represent rather a spectator species, which we will further denoted as $\mathrm{S} 1$.

Previously, the prominent band at $1120 \mathrm{~cm}^{-1}$ was assigned to a stretching vibration of a single $\mathrm{C}-\mathrm{O}$ bond with the $\mathrm{O}$ atom being coordinated to a metal atom of the underlying substrate ${ }^{29,32-38}$; also note that this band appears only under the reaction conditions in presence of $\mathrm{H}_{2}$ and was not observed in molecular acrolein on $\mathrm{Pd}$ at $100 \mathrm{~K}$ or in acrolein ice. The high intensity of this band additionally suggests the formation of a $\mathrm{C}-\mathrm{O}$ single bond exhibiting a large dynamic dipole moment, which results in high IR intensity. Noteworthy, we found a strong correlation between the intensity evolution of the band at $1120 \mathrm{~cm}^{-1}$ with time and the propenol production rate: it evolves in the spectrum 1 during the first $45 \mathrm{~s}$ of reaction, substantially grows in intensity in the spectra (2) and (3) related to the time period with highest reactivity, decreases while the formation rate of molecular propenol decreases (spectrum 4) and completely vanishes in the very last spectrum when the surface fully deactivates. This correlated appearance and development of the surface adsorbates related to the vibration at $1120 \mathrm{~cm}^{-1}$ and the formation rates of molecular propenol monitored in the gas phase strongly suggest that the related surface species must be a direct reaction intermediate (RI). Several other bands, appearing at $1090 \mathrm{~cm}^{-1}, 1463-1450 \mathrm{~cm}^{-1}$, $2966 \mathrm{~cm}^{-1}$ and $2980 \mathrm{~cm}^{-1}$, follow an identical time evolution pattern ${ }^{12-14}$ and therefore can be also associated with RI. The vibrations at $2966 \mathrm{~cm}^{-1}$ and $2980 \mathrm{~cm}^{-1}$ are characteristic to $\mathrm{C}-\mathrm{H}$ stretching 
modes with the band at $2980 \mathrm{~cm}^{-1}$ being typically assigned to a $\mathrm{C}-\mathrm{H}$ fragment, in which the carbon atom is involved into the $\mathrm{C}=\mathrm{C}$ bond. ${ }^{39}$

Combining all spectroscopic signatures correlated with the evolution of propenol formation rate, we identified the chemical structure of the reaction intermediate as propenoxy species $\left(\mathrm{CH}_{2}=\mathrm{CH}-\mathrm{CH}_{2}-\mathrm{O} \cdots \cdot \mathrm{Pd}\right)$. This species is formed via attachment of one $\mathrm{H}$ atom to the $\mathrm{C}$ atom in the carbonyl group, which results in formation of a single $\mathrm{C}-\mathrm{O}$ bond, exhibiting the vibrational frequency of $1120 \mathrm{~cm}^{-1}$. In this species, the $\mathrm{O}$ atom is attached to $\mathrm{Pd}$ atom forming an $\eta_{1}-(\mathrm{O})$ configuration; Figure $3 \mathrm{~b}$ shows the proposed structure of the reaction intermediate in blue color. Note that the $\mathrm{C}=\mathrm{C}$ bond is preserved in this RI as suggested the vibrational mode at $2980 \mathrm{~cm}^{-1}$ assigned to a vinyl group. ${ }^{24,40-41}$ The further half-hydrogenation step of this bond - incorporation of a second hydrogen into the $\mathrm{O}-\mathrm{Pd}$ bond - directly transfers the propenoxy reaction intermediate into the final product propenol.

The last two spectra in Figure $3 \mathrm{~b}$ were recorded after the propenol formation rate strongly decreased (spectrum 4) or completely vanished (the last spectrum). All spectral modes associated with the propenoxy reaction intermediate are not visible in these spectra. Additionally, a new mode at $1330 \mathrm{~cm}^{-1}$ emerges, which was previously assigned to the umbrella bending mode of the methyl group in ethylidyne species. ${ }^{42-43}$ The appearance of this new band evidences acrolein decomposition via decarbonylation resulting in carbonaceous deposits - ethylidyne species - and a fragment involving the carbonyl group of acrolein previously described in the literature. ${ }^{44-48}$ Since the propenol formation rate decreases over time and this process is correlated with the appearance of ethylidyne-like species, it can be speculated that decomposition products lead to the catalyst's deactivation by blocking the surface sites.

4. Evolution of the spectator species and the reaction intermediate. Correlation between the abundance of the surface reaction intermediate and the formation rate of propenol.

It is important to point out, that selective hydrogenation of acrolein to propenol proceeds not on the pristine $\mathrm{Pd}(111)$, but on the surface, whose adsorption and reactive properties are strongly modified by the presence of a dense overlayer of oxopropyl spectator species $S 1$. This conclusion was made based on the time evolution of the $\mathrm{S} 1$ species (the band at $1755 \mathrm{~cm}^{-1}$ ) vs. the reaction intermediate (the band at $1120 \mathrm{~cm}^{-1}$ ) as show in the series of spectra in Figure 4a. The spectra (1) and (2), which were obtained during the induction period, clearly show that the oxopropyl (S1) species are rapidly formed, while no reaction intermediate can be observed during this time. Only after about 16-20 s of acrolein exposure, which corresponds to the onset of propenol evolution in the gas phase, the reaction intermediate appears on the surface (spectra 3 and 4). The coverage of the oxopropyl spectator species accumulated on the surface during the induction period, which was determined via King-Wells-type sticking coefficient measurements ${ }^{41}$, amounts to about 0,25 ML with respect to the total amount of surface Pd atoms. This means that about one S1 molecule was accumulated per four Pd surface by the end of the induction period. This finding suggests that a dense overlayer of oxopropyl species must be formed to induce the desired partial hydrogenation of the carbonyl group to form the propenoxy intermediate. Most likely, the ensemble of the 
adsorbed oxopropyl spectator species imposes a strong steric confinement on the adsorption geometry of newly incoming acrolein molecules. In this case, the adsorption of acrolein via $\mathrm{C}=\mathrm{C}$ bond can be suppressed, so that acrolein can approach the surface only via the carbonyl group, which leads to exclusive hydrogenation of the $\mathrm{C}=\mathrm{O}$ bond. Another feasible scenario can be based on the dynamic effects, when the potential energy surface of the S1-coverd Pd(111) steers the incoming acrolein molecules such that they enter the near-surface region only with the O-end. Clearly, the $\mathrm{C}=\mathrm{O}$ bond of acrolein cannot be hydrogenated on pristine $\operatorname{Pd}(111)$ and a strong modification of the surface by additional surface species - in this case oxopropyl spectator species - is required to trigger the reaction route to propenol.

In view of these findings, the oxopropyl S1 species cannot be considered merely as a spectator but rather as a key component turning the catalyst exceptionally selective towards $\mathrm{C}=\mathrm{O}$ bond hydrogenation. In this case, the dense layer of the oxopropyl species governs the interaction of newly incoming acrolein molecules with the catalytic surface resulting in a specific acrolein adsorption via the $\mathrm{O}$-end. This synergistic action of the catalytically active $\mathrm{Pd}$ surface and the adsorbed oxopropyl overlayer on the activity and selectivity of the surface process can be clearly referred to ligand-directed heterogeneous catalysis, in which the surface adsorbates play a decisive role in determining the course of the reaction along a particular reaction pathway.

The correlated evolution of the surface RI propenoxy species and the desired target product propenol was further investigated by in operando IRAS combined with the gas phase analysis via mass spectrometry. Figure $4 \mathrm{~b}$ shows the gas phase propenol formation rate (blue line) plotted as a function of time along with the integral intensity of the IR band at $1120 \mathrm{~cm}^{-1}$ (black symbols), which is the most intense band related to propenoxy reaction intermediate. The integral intensity of this band is roughly proportional to the surface coverage of the propenoxy species. It can be clearly seen that the propenol formation rate measured in the gas phase closely follows the concentration of the propenoxy species on the surface during the entire reaction, additionally supporting our assignment of these surface species to a reaction intermediate, which directly participates in selective hydrogenation of carbonyl group.

Summarizing, the selectivity in hydrogenation of the $\mathrm{C}=\mathrm{O}$ bond in acrolein over $\mathrm{Pd}(111)$ critically depends on the modification of the catalyst's surface with a layer of the oxopropyl spectator species formed during the induction period (the proposed model is shown in Figure 5a). These oxopropyl surface modifiers rendering the catalyst exceptionally chemoselective are formed as a result of the addition of one hydrogen atom to the $\mathrm{C}=\mathrm{C}$ entity of the original molecule. After formation of a densely packed oxopropyl layer, acrolein can adsorb only via the $\mathrm{C}=\mathrm{O}$ bond to form the propenoxy reaction intermediate shown in Figure $5 \mathrm{~b}$ that can undergo a further hydrogenation step resulting in propenol formation. By monitoring the surface composition in the course of the reaction via IRAS, a correlated evolution of the RI on the surface and the reaction rate towards propenol was observed, which additionally confirms the assignment of the propenoxy species to the direct surface reaction intermediate.

\section{Origins of decreasing selectivity in acrolein partial hydrogenation on Pd(111).}


The highest activity and selectivity for acrolein partial hydrogenation was observed between $250-270 \mathrm{~K}$. Below and above this temperatures, both the activity and selectivity significantly dropped (for the complete dataset $\mathrm{see}^{14}$ ). In order to understand the microscopic origins of this phenomenon, we performed systematic kinetic measurements under isothermal reaction conditions combined with the monitoring of the surface composition via in operando IRAS at seven different temperatures in the range $220-350 \mathrm{~K}$. The particular focus of these studies was at the atomistic understanding of the chemical composition of the inactive surface as compared to the highly active and selective surface modified with a densely packed oxopropyl overlayer.

Figure 6a displays the reaction rate towards propenol and propanal recorded in the gas phase at three selected temperatures: 220,270 and $320 \mathrm{~K}$. The acrolein exposure starts at the moment indicated as zero. At all investigated temperatures, the formation rate of propanal was found to be quite small. In contrast, the formation rate of propenol strongly depends on the temperature exhibiting a pronounced maximum at $270 \mathrm{~K}$. The observed time and temperature dependence of competing reaction routes most likely arises from a complex interplay between different elementary reaction steps and adsorption/desorption processes, which critically influences the overall performance of the catalytic surface. In the following, we will separately discuss the microscopic origins of low hydrogenation activity and selectivity in the low $(<250 \mathrm{~K})$ and high $(>$ $300 \mathrm{~K}$ ) temperature regimes.

At $220 \mathrm{~K}$, only very low reaction rates were detected for both reaction pathways over $\operatorname{Pd}(111)$ (Figure 6a). Figure $6 \mathrm{c}$ displays the infrared spectra recorded on the surface turning over at $220 \mathrm{~K}$ to probe its chemical composition (black lines). For comparison, the IR spectra measured at $270 \mathrm{~K}$, at which the highest formation rate of propenol was observed, are plotted as grey traces to illustrate the differences between the surface composition of the non-active and non-selective vs. highly active and selective surface.

The only vibrational band appearing at $220 \mathrm{~K}$ is the weak band near $1750 \mathrm{~cm}^{-1}$, which has nearly the same frequency as the $\mathrm{C}=\mathrm{O}$ bond in the oxopropyl spectator species, yet considerably lower intensity. This observation suggests that the same type of the surface species - oxopropyl can be formed at lower temperatures, but its concentration is noticeably lower than at $270 \mathrm{~K}$. Most likely, only a minor fraction of the catalyst's surface is covered by the oxopropyl spectator species in this temperature range, resulting in a lower formation rate of propenol as compared to a fully spectator-covered surface. In contrast, the propanal is formed at a significantly higher rate than at $270 \mathrm{~K}$ suggesting more efficient hydrogenation of the $\mathrm{C}=\mathrm{C}$ bond at the spectator-free $\operatorname{Pd}(111)$ surface.

The observed reaction behavior at $220 \mathrm{~K}$ most likely indicates that the catalyst's surface consists of two regions: $(i)$ a small fraction of the metal is covered by an overlayer of the oxopropyl spectator species rendering this part of the surface chemoselective towards propenol formation and (ii) a larger fraction of the surface remains spectator-free and performs hydrogenation of the $\mathrm{C}=\mathrm{C}$ bond to form propanal. 
Above $300 \mathrm{~K}$, the activity and the selectivity of both reaction pathways drastically decrease as compared to $250-270 \mathrm{~K}$ (Figure $6 \mathrm{a}$ ). The composition of the surface probed under the reaction conditions at $320 \mathrm{~K}$ by IRAS is shown in Figure $6 \mathrm{~b}$ (black lines), while the grey lines are related to the reaction temperature of $270 \mathrm{~K}$ and are displayed for comparison. At the beginning of acrolein exposure, two new vibrational bands evolve at $1850 \mathrm{~cm}^{-1}$ and $1800 \mathrm{~cm}^{-1}$ together with a prominent peak at $1335 \mathrm{~cm}^{-1}$. The first two peaks gain in intensity and shift to higher frequencies $\left(1880 \mathrm{~cm}^{-}\right.$ ${ }^{1}$ ) in the course of the reaction. The vibrational peaks observed in the range $1800-1880 \mathrm{~cm}^{-1}$ and the frequency shifts induced by the increasing coverage point to accumulation of $\mathrm{CO}$ molecules on $\operatorname{Pd}(111){ }^{49}$ The non-linear coverage dependence of the CO peak intensities and of the corresponding vibrational frequencies results from strong dipole coupling and "intensity borrowing" effects described earlier in the literature. ${ }^{50}$ The band at $1335 \mathrm{~cm}^{-1}$ evidences formation of ethylidyne species.

The observed spectroscopic signatures suggest that acrolein almost entirely decomposes at $320 \mathrm{~K}$ to $\mathrm{CO}$ and ethylidyne that irreversibly accumulate on the surface and block the surface sites. A similar decomposition process was also detected at $270 \mathrm{~K}$ as indicated by formation of ethylidyne species, however, the decomposition occurs to a significantly lesser extent as compared to $320 \mathrm{~K}$. Further, no molecular CO was observed at $270 \mathrm{~K}$, suggesting that acrolein most likely decomposes to a $\mathrm{H}-\mathrm{C}=\mathrm{O}$ fragment, which exhibits the frequency of the $\mathrm{C}=\mathrm{O}$ stretching vibration similar to carbonyl vibration in oxopropyl species. With this, the nature of the adsorbates formed on the catalyst at $320 \mathrm{~K}$ suggests a large extent of acrolein decomposition to $\mathrm{CO}$ and ethylidyne species, which poison the catalyst and lead to substantial lowering of the activity and selectivity for both reaction pathways.

It should be noted that in our studies carried out in the full temperature range $220-350 \mathrm{~K}$, two types of correlated behavior between the presence of oxopropyl spectator species and formation of the desired reaction product propenol were observed. First, if a dense layer of oxopropyl spectator species was detected by IRAS, both the propenoxy RI and the target product propenol were formed on the surface and in the gas phase, correspondingly. Vice versa, in case when only negligible amount or no spectator species were formed on the catalyst's surface, neither the propenoxy surface reaction intermediate and nearly nor propenol were observed. The latter negative correlation provides an additional support for out hypothesis on the decisive role of the densely-packed oxopropyl layer in rendering the surface highly selective towards $\mathrm{C}=\mathrm{O}$ bond hydrogenation.

\section{Acrolein hydrogenation over Pd NPs supported on $\mathrm{Fe}_{3} \mathrm{O}_{4}$.}

Supported Pd nanoparticles show negligible hydrogenation activity towards propenol as shown in Figure 2c and 2d, even though the (111) facets represent about $80 \%$ of the nanoparticles' surface area. In order to understand this drastic difference between the catalytic performance of Pd nanoparticles vs. the single crystal, this reaction was investigated over Pd NPs of various sizes supported on model $\mathrm{Fe}_{3} \mathrm{O}_{4}(111) / \mathrm{Pt}(111)$ oxide film. ${ }^{15-16}$ Specifically, the evolution of the surface 
species was followed by IRAS during the course of the reaction and the chemical composition of the surface species was compared to that one observed on $\operatorname{Pd}(111)$ under the identical conditions.

Figure 7a shows the reaction rates for both competing pathways - towards propanal and propenol formation - measured over Pd nanoparticles with the average size of about $12 \mathrm{~nm}$ at 270 $\mathrm{K}$. While no propenol formation was observed on this surface, minor amounts of propanal could be detected as a gas phase product after a short induction period of about $5 \mathrm{~s}$. However, the reactivity decreases rapidly after passing a small maximum. The observed exclusive hydrogenation of the $\mathrm{C}=\mathrm{C}$ bond over Pd nanoparticles agrees well with the earlier reports on Pd-based powdered catalytic materials showing that acrolein can be hydrogenated only to propanal. ${ }^{17,19}$

Figure $7 \mathrm{~b}$ shows the IR spectra $(1-3)$ obtained during the reaction; the spectra correspond to the time regions $1-3$ shown on the kinetic curve in the Figure 7a. Obviously, completely different surface adsorbates are formed during the reaction on the Pd particles as compared to $\operatorname{Pd}(111)$. The spectra exhibit prominent vibrations in the frequency range $1800-1960 \mathrm{~cm}^{-1}$, which appear first at lower frequencies and become more intense and blue shifted with increasing reaction time. These vibrational features can be clearly assigned to $\mathrm{CO}$ molecules being accumulated on the catalyst's surface, most likely as a result of facile acrolein decarbonylation. This conclusion is supported by the previous studies on $\mathrm{CO}$ adsorption at $\mathrm{Pd}$ nanoparticles of different sizes. ${ }^{51-57}$ Briefly, CO molecules accommodated on the (111) terraces $\left(1800-1960 \mathrm{~cm}^{-1}\right)$ can be discriminated from $\mathrm{CO}$ adsorbed at low-coordinated surface sites, such as the particles edges and corners, resulting in a sharp IR peak at appr. $1970 \mathrm{~cm}^{-1}$. Remarkably, the decarbonylation process of acrolein proceeds very efficiently on Pd nanoparticles already at $270 \mathrm{~K}$, while only minor accumulation of ethylidyne(-like) species resulting from acrolein decomposition and no $\mathrm{CO}$ formation was detected on $\mathrm{Pd}(111)$ at this temperature. Note that the studied Pd clusters are mostly terminated by the (111) facets with about $80 \%$ of surface Pd atoms being incorporated in the regular (111) terraces ${ }^{58}$ Hence, the difference in the decomposition behavior most likely originates from the presence of edges and corners on Pd NPs, comprising about 20\% of the surface Pd atoms, which are probably more active in acrolein decomposition than the (111) terraces. We believe that $\mathrm{CO}$ molecules form at the edges and corners of a Pd nanoparticle and diffuse across the surface to the terraces, where they build a layer of adsorbed CO. This CO overlayer blocks the (111) terraces and with this hinders formation of a dense oxopropyl spectator layer, which is a crucial prerequisite for turning the surface chemoselective towards hydrogenation of the $\mathrm{C}=\mathrm{O}$ bond.

The decomposition products are non-uniformly distributed over Pd nanoparticles. Figure $7 \mathrm{~b}$ shows the composition of the species remaining on the catalyst's surface after it's complete deactivation (spectrum 3, black line). For comparison, the spectrum of a monolayer of CO molecules measured on pristine Pd nanoparticles is shown in the same plot (grey line). While the intensities of the vibrational bands related to CO adsorbed at the (111) terraces $\left(1800-1960 \mathrm{~cm}^{-}\right.$ ${ }^{1}$ ) are similar on both surfaces, striking difference in the abundance of the $\mathrm{CO}$ species adsorbed at the particles edges (vibration at $1970 \mathrm{~cm}^{-1}$ ) can be observed. The intensity of this vibration is very high on the pristine Pd NPs, however, this band almost completely disappears at the late stages of 
the reaction (spectrum 3). Note that the low-coordinated sites at the Pd NPs are the strongest binding sites for $\mathrm{CO}$ molecules ${ }^{59}$, so that on the pristine NPs $\mathrm{CO}$ is expected to adsorb at these sites first. The fact that edges and the corners on the deactivated surface cannot adsorb $\mathrm{CO}$, while the (111) terraces do accumulate $\mathrm{CO}$, most likely means that the low-coordinated site are occupied by some other species having even higher binding energy than $\mathrm{CO}$ molecules. These strongly bonded surface species could be carbon or $\mathrm{CH}_{\mathrm{x}}$ fragments resulting from acrolein dehydrogenation. This hypothesis is in line with our previous studies demonstrating the preferential adsorption of strongly dehydrogenated carbonaceous deposits at the edges of $\mathrm{Pd}$ nanoparticles. ${ }^{6}$ Since these species are not visible by IRAS, it can be speculated that ethylidyne species resulting from acrolein decarbonylation further dissociate to form carbon or $\mathrm{CH}_{\mathrm{x}}$ fragments, which preferentially occupy the low-coordinated sites.

\section{Acrolein hydrogenation over Pd nanoparticles: tuning the reaction conditions to populate oxopropyl spectator species.}

Having detected a clear correlation between the presence of the ligand-like oxopropyl species and high selectivity towards hydrogenation of the $\mathrm{C}=\mathrm{O}$ bond, we systematically tuned the reaction conditions - reactant fluxes and surface temperature - to populate oxopropyl groups also on Pd nanoparticles. It should be pointed out that besides the target reaction, numerous processes can occur simultaneously on the catalytic surfaces, including decomposition of the reactants and the formation of the spectator species. By tuning the reactant fluxes and the surface temperature, it is feasible to affect the relative rates of these processes and with this change the relative abundance of the related surface species. In our studies, we made an attempt to find the conditions, at which the concentration of the oxopropyl spectator species could be maintained at a sufficiently high level - at least at a certain area of Pd NPs - so that these modified surface regions turn selective towards $\mathrm{C}=\mathrm{O}$ bond hydrogenation. Indeed, we were able to establish such experimental conditions, at which formation of propenol over Pd nanoparticles was observed, yet in low amounts. ${ }^{15-16}$

Figure 8a shows the propanal (black line) and propenol (gray line) formation rates during acrolein hydrogenation over $12 \mathrm{~nm}$ Pd particles at $250 \mathrm{~K}$, which were obtained at an acrolein flux approximately 3 times lower than applied in the experiments shown in Figure 7 (for more experimental details see $^{15-16}$ ). Under these reaction conditions, not only the unwanted product propanal is formed but also noticeable amounts of the target product propenol can be detected. Similarly to the reactivity behavior observed on $\operatorname{Pd}(111)$, an induction period can be observed, which indicates that the $\mathrm{Pd}$ nanoparticles must also accumulate a certain amount of acroleinderivatives prior to the onset of propenol formation.

The composition of the catalysts' surface was investigated by IRAS under the reaction conditions, the corresponding spectra are shown in Figure 8b. The IRAS spectrum (1) collected during the induction period exhibits only one band at $1755 \mathrm{~cm}^{-1}$ that is assigned to the oxopropyl spectator species. This observation proves that the oxopropyl spectator species is formed at least at the part of the nanoparticle's surface during the induction period under the given experimental 
conditions. Similarly to $\operatorname{Pd}(111)$, the onset of propenol evolution in the gas phase is detected only after the oxopropyl species appear on the surface.

The IRAS spectra collected after the induction period (labeled (2) through (4) in Figure 8b) show two additional bands at $1855 \mathrm{~cm}^{-1}$ and $1670 \mathrm{~cm}^{-1}$, which are related to $\mathrm{CO}$ molecules adsorbed at the three-fold hollow sites on the Pd nanoparticles and molecularly adsorbed acrolein, respectively. Appearance of the band at $1855 \mathrm{~cm}^{-1}$ clearly shows that the decomposition of acrolein to $\mathrm{CO}$ and other hydrocarbon fragment still occurs on Pd nanoparticles even if a significantly lower acrolein flux is applied. However, this process seems to be slow, so that the decomposition products accumulate on the surface at a significantly lower rate as compared to the reaction conditions applied in the experiments shown in Figure 7. Most likely, the slow rate of acrolein decomposition allows at least a part of the surface to form a layer of the spectator species rendering the nanoparticles active towards hydrogenation of the carbonyl group.

It should be emphasized, that also the catalytic behavior of Pd nanoparticles shows the same positive dependence observed on single crystalline $\mathrm{Pd}$ : the gas phase product propenol is detected only oxopropyl spectator species are present on the surface. This finding additionally confirms our conclusion on the critical role of these spectator species in selective hydrogenation of acrolein to propenol.

\section{8. $\quad$ Concluding Remarks}

In this perspective, we summarized our recent mechanistic studies on selective partial hydrogenation of acrolein towards the desired reaction product - unsaturated alcohol propenol over two model surfaces: $\mathrm{Pd}(111)$ and $\mathrm{Pd}$ nanoparticles supported on $\mathrm{Fe}_{3} \mathrm{O}_{4} / \mathrm{Pt}(111)$ film. We demonstrate that the desired reaction pathway -hydrogenation of the carbonyl group - can proceed with $100 \%$ selectivity and high activity over $\operatorname{Pd}(111)$. However, this process occurs not on the pristine metal but requires a strong modification of the surface structure with a dense layer of ligand-like oxopropyl species. These species result from acrolein hydrogenation on the $\mathrm{C}=\mathrm{C}$ bond with only one hydrogen atom in the induction period at the beginning of reaction. Once this layer of surface modifiers/ligands is formed, acrolein interaction with the catalytic surface dramatically changes leading first to appearance of the surface reaction intermediate - propenoxy species, which is formed via hydrogenation of the $\mathrm{C}=\mathrm{O}$ bond with one hydrogen atom, followed by the further hydrogenation step to form the final product propenol. The nature of the corresponding surface modifier/ligand (oxopropyl species) and well as the surface reaction intermediate (propenoxy species) was determined by IRAS. By simultaneous monitoring the adsorbates formed on the surface turning over via infrared spectroscopy and the formation rate of the target product propenol, we were able for the first time to experimentally detect a strong correlation between the evolution of the reaction intermediate on the surface and the formation rate of the reaction product in the gas phase. Based on this correlation, we were able to prove that the propenoxy surface species is a reaction intermediate, which is directly involved into the overall reaction mechanism, while the other adsorbates were identified as ligand-like modifiers or decomposition products. Additionally, a clear correlation between the absence of the oxopropyl surface modifiers and the 
absence of the hydrogenation activity towards propenol was demonstrated. On Pd nanoparticles, acrolein readily dissociates to produce $\mathrm{CO}$ and some strongly dehydrogenated $\mathrm{CH}_{\mathrm{x}}$ fragments or carbon, which inhibit formation of a dense ligand-like oxopropyl layer and with this prevents the desired reaction route. A similar scenario also takes place on $\operatorname{Pd}(111)$ at elevated temperature.

The revealed reaction mechanism clearly demonstrates the highly important role of the surface modifiers in directing the surface processes towards the desired reaction pathway. With this, the discussed surface reaction can be related to ligand-directed heterogeneous catalysis, in which the synergy between the high catalytic activity of the metal surface and the specific adsorbate-adsorbate interactions - modifier/ligand with the reactant/reactant intermediate - plays a crucial role for the overall activity and selectivity.

Despite the clear experimental evidences on the crucial role of the oxopropyl reaction modifier in selective hydrogenation of acrolein, its exact role in turning the surface highly selective is still not fully rationalized. There are a few atomistic scenarios that can be potentially responsible for the observed phenomena. First, the densely packed oxopropyl overlayer can impose a geometric constrain on the adsorption geometry of newly incoming acrolein molecules, so that they can adsorb only via the $\mathrm{C}=\mathrm{O}$ bond on this ligand-modified surface, but nor via a $\mathrm{C}=\mathrm{C}$ bond, which is possible on the pristine $\operatorname{Pd}(111)$ surface. Another feasible scenario can be based on the dynamic effects, when the potential energy surface of the ligand-covered $\operatorname{Pd}(111)$ steers the incoming acrolein molecules in such a way that they enter the near-surface region only with the O-end. Further theoretical calculations are required to obtain more insights into the microscopic origins of this phenomenon.

While in the discussed reaction system the surface modifiers were formed from the partial hydrogenation of the reactant at the initial stages of the reaction, this is not the only feasible route to produce ligand-modified catalysts. An appropriate modifier - not necessarily a derivative of the reactant - can be adsorbed on the surface prior the reaction.

There is a growing number of reports in the catalytic literature on heterogeneously catalyzed reactions proceeding on ligand-modified surfaces. ${ }^{5,8,61-69}$ A large body of these reports is related to enantioselective heterogeneous catalysis on chirally-modified surfaces. In this type of catalysis, the surfaces are modified by adsorption of chiral adsorbates, exhibiting enantiospecific interaction with a pro-chiral reactant, which directs the catalytic process towards formation of only one enantiomeric form of the product. Generally, imposing chirality to surface processes can be performed in two different ways: ( $i$ ) formation of chiral supramolecular structures, such as e.g. adsorption of tartaric acid on $\mathrm{Ni}^{69-70}$ In this case, the incoming prochiral molecules interact with the supramolecular structure as a whole, e.g. by adsorbing in chiral "pockets". (ii) Adsorption of chiral modifiers, which form 1:1 complexes with the prochiral reactants. In this chiral complexes, the prochiral reactant has a specific adsorption geometry with respect to the underlying metal substrate, which allows only asymmetric chemical transformations resulting in enantiopure puduct. ${ }^{69,71}$ One of the first reported examples of such type of chiral interactions is enantioselective hydrogenation of esters over chincona-modified Pt catalysts. 5, 64, 71 Recently, an impressive 
progress was made by a number of groups studying the mechanisms of enantioselective processes at the atomistic level; some of these studies are summarized in the recent reviews. ${ }^{5-6,9-10}$

Besides of enantioselective heterogeneous catalysis, there is an increasing number of reports related to ligand-induced catalysis for non-chiral systems. ${ }^{4,8,61,65,67-68}$ In this type of surface processes, the pre-adsorbed surface modifiers induce specific adsorbate-adsorbate interactions with the reactant and by this turn the catalytic surface highly selective. The atomistic origins of this phenomenon can be tentatively divided into geometric- and electronic-related effects. While the geometric effects are attributed to the modification of the physical structure of the surface, such as e.g. building of surfaces ensembles being able to specifically interact with a reactant, surface restructuring or molecular recognition leading to formation of 1:1 modifier-reactant complexes, the electronic effects result from modifier-induced changes in the distribution of the electron density near a surface. This latter type of surface modification can act via e.g. dipole-dipole coupling producing electrostatic forces on the surface that alter the way the nearby adsorbates bind or via electron donation or withdrawal from the surface by a modifier, especially when the modifier is significantly more electropositive or electronegative than the metal atoms. Also a competition for the electron density of an underlying metal between different adsorbates - the modifiers and the reactants - can be related to the electronic effect, which might affect the binding strength ${ }^{72}$ and the adsorption geometry of the reactants on the ligand-modified surfaces. Recently, a number of reports were published on this subject. Thus, Lambert et al ${ }^{68}$ demonstrated that co-adsorbed sulfur induces the adsorbate geometry changes that drastically improve selectivity in crotonaldehyde hydrogenation over copper. Medlin et $\mathrm{al}^{66}$ demonstrated in a number of studies that surface "crowding" with thiolate-based self-assembled monolayers and other organic surface modifies can be used to control the orientation of various multi-unsaturated reactants and considerably improve the selectivity towards the desired reaction pathway. Bäumer et $\mathrm{al}^{61}$ reported their studies on metallic nanoparticles modified with different types of ligands and ligand shells, which were found to be beneficial for the overall activity and selectivity of oxidative processes. The authors discussed the ligand effects in terms of the tuning the metal-support interaction, protection of the metal nanoparticles against chemical modification, e.g. against oxidation, as well as preventing particles sintering. These and many other studies on ligand-induced or -assisted catalysis demonstrate a great potential of this emerging technology to finely tune the surface structure to provide the best possible environment for the desired series of the reaction steps. This type of surface modification allows to synergistically combine the inherent properties of heterogeneous and homogeneous catalysis by connecting the high activity of a catalytic surface with a specific adsorbate-adsorbate interaction between the modifier and the reactant to turn the overall catalytic system highly active and selective. In order to implement this technology into the rational design of new catalytic materials, more atomistic-level insights into the surface phenomenal directing adsorbate-adsorbate interaction needs to be gained in the microscopic-level studies, particularly on the details of the adsorption geometries of the modifier/reactant complexes, details of the reaction kinetics on the ligand-modified surfaces, the feasible ligand-induced changes of the electronic structures etc. A joint effort by the surface science community to address these issues would be highly desirable. 


\section{Acknowledgment}

I am grateful to my collaborators as they appear in the references, specifically to Karl-Heinz Dostert, Casey P. O'Brien, Francesca Mirabella and Hans-Joachim Freund. Financial support from the European Research Council (ERC Starting Grant ENREMOS, 335205) is gratefully acknowledged. 


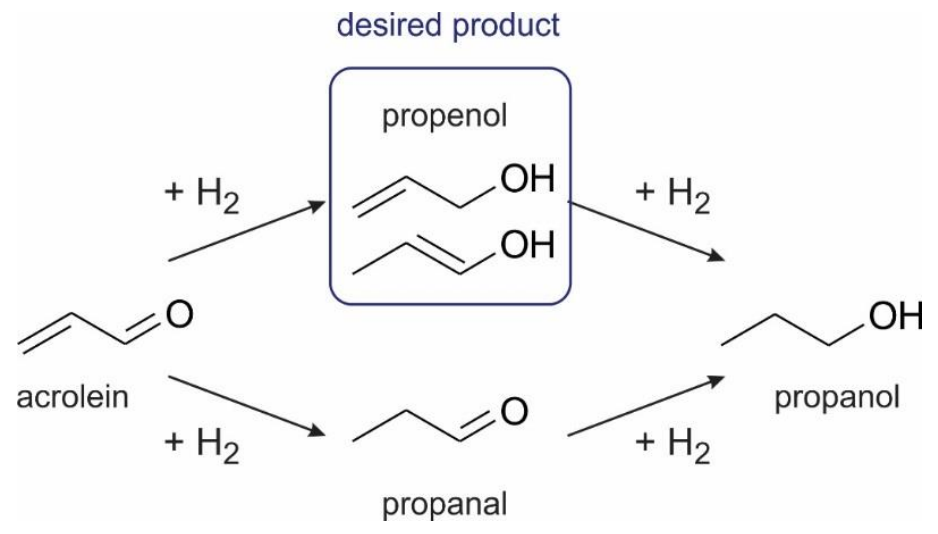

Figure 1. Competing reaction pathways in partial selective hydrogenation of acrolein. 
$\operatorname{Pd}(111)$
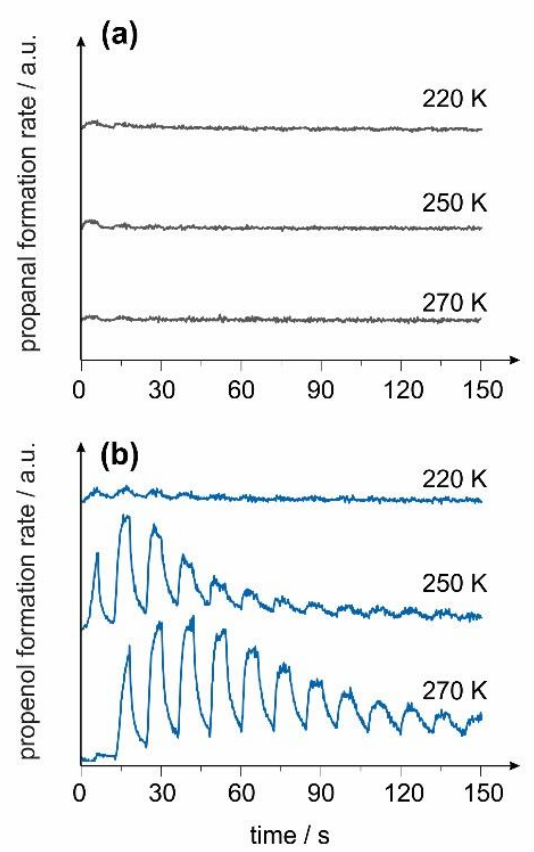

Pd Nanoparticles $/ \mathrm{Fe}_{3} \mathrm{O}_{4} / \mathrm{Pt}(111)$
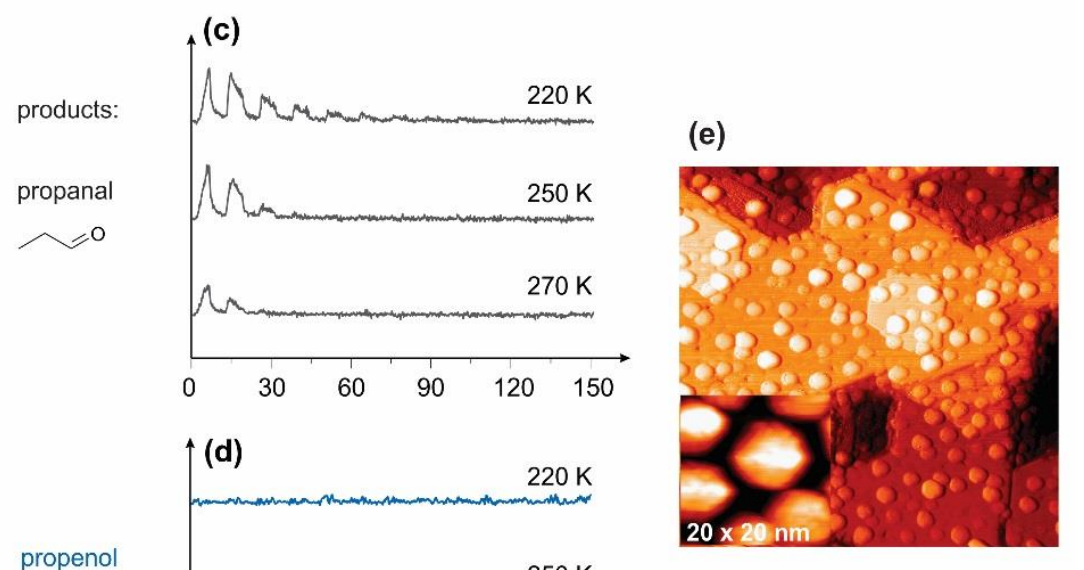

Figure 2. (a) - (d) Formation rates of the reaction products - propanal (upper row) and propenol (lower row) - on Pd(111) (a und b) and on $12 \mathrm{~nm}$-sized supported Pd nanoparticle (c and d) during continuous dosing of $\mathrm{H}_{2}$ and pulsed dosing of acrolein at different temperatures (after $\left[{ }^{12}\right]$ ); (e) STM image of Pd NPs supported on $\mathrm{Fe}_{3} \mathrm{O}_{4} / \mathrm{Pt}(111)$ employed in this study (from $\left[{ }^{58}\right]$ ). 

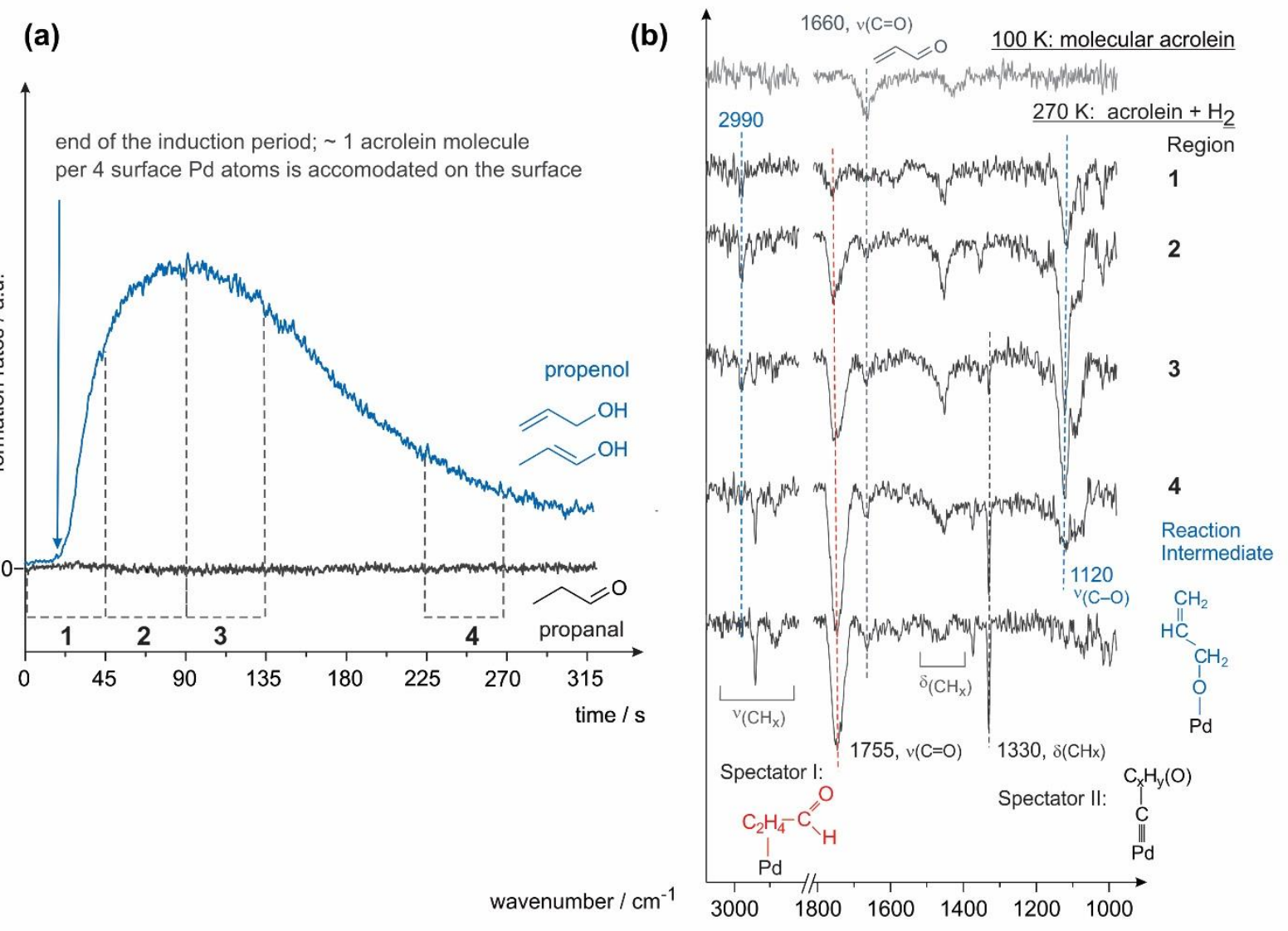

Figure 3. (a) Propenol (blue line) and propanal (black line) formation rates of on $\operatorname{Pd}(111)$ at 270 $\mathrm{K}$ under continuous exposure of $\mathrm{H}_{2}$ and acrolein; the time zero corresponds to the onset of acrolein exposure. (b) IR spectra recorded for molecularly adsorbed acrolein at $100 \mathrm{~K}$ on pristine $\mathrm{Pd}(111)$ (1, grey line) and on $\mathrm{Pd}(111)$ at $270 \mathrm{~K}$ under the reaction conditions during continuous exposure to acrolein and $\mathrm{H}_{2}(2-4)$. Spectra $2-4$ correspond to the time regions $2-4$ indicated in (a); the last spectrum was recorded after complete catalyst deactivation (after $\left.\left[{ }^{14}\right]\right)$. 
(a)

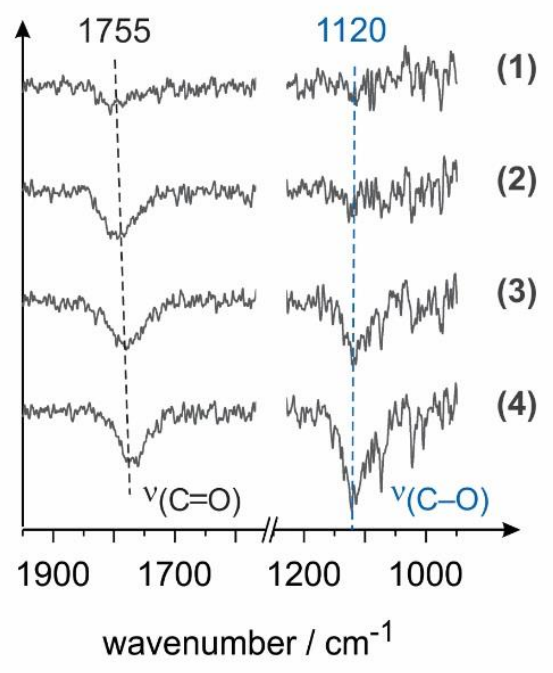

(b)

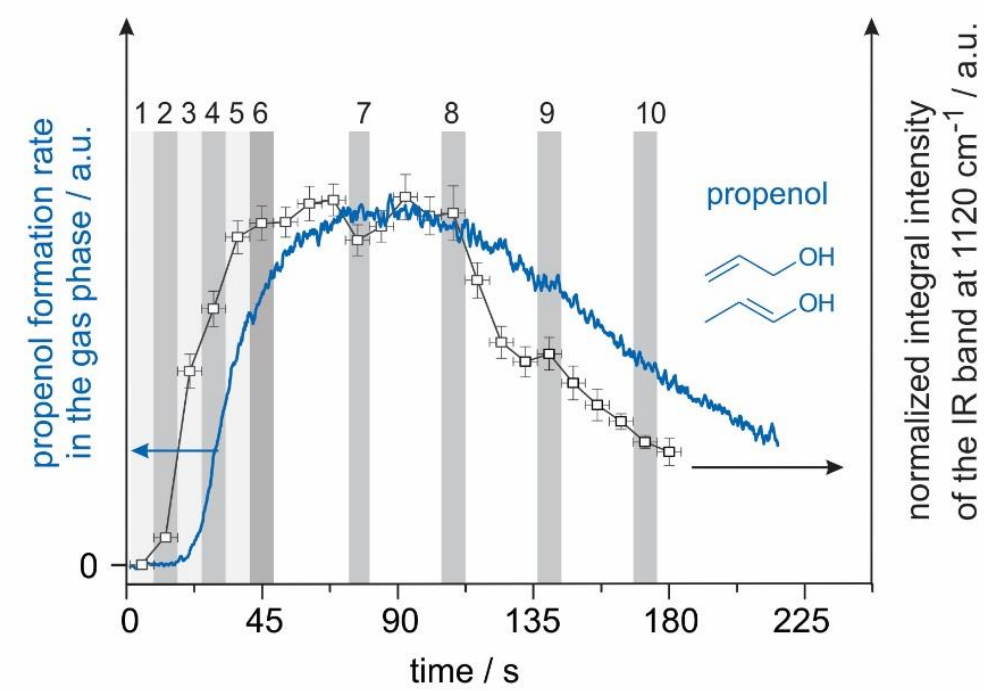

Figure 4. (a) IR spectra obtained over the $\mathrm{Pd}(111)$ at $270 \mathrm{~K}$ under the reaction conditions during continuous exposure to acrolein and $\mathrm{H}_{2}$. Shown are only the vibrational regions relevant to the reaction intermediate and the spectator species, which are indicated with dotted lines. (b) Strongly correlated evolution of the propenol formation rate in the gas phase (blue line) and the surface concentration of the reacton intermediate estimated from the integral intensity of the IR band at $1120 \mathrm{~cm}^{-1}$ (open black symbols). The intergal intensities are calculated from the series of spectra shown in $\left[{ }^{14}\right]$. 
induction period:

formation of an overlayer of spectator species

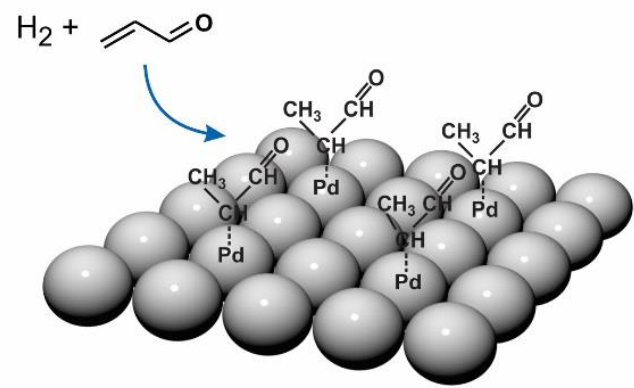

period of high activity: formation of the surface reaction intermediate on the spectator-modified surface

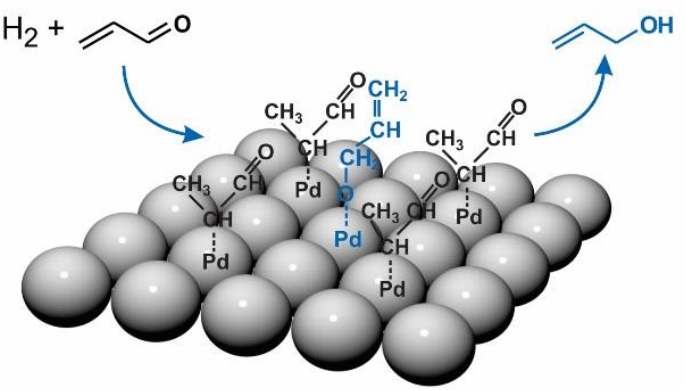

Figure 5. Proposed chemical composition of the highly selective ligand-modified $\operatorname{Pd}(111)$ surface: (a) During the induction period, acrolein adsorbs on the surface and forms an oxopropyl surface species covalently bonded to $\mathrm{Pd}$, which result from half-hydrogenation of the $\mathrm{C}=\mathrm{C}$ bond with one hydrogen atom. A densely packed layer of the oxopropyl spectator species is formed with the formal coverage close to $0,25 \mathrm{ML}$ with respect to the total number of surface Pd atoms. (b) The oxopropyl-layer renders the surface highly chemoselective towards hydrogenation of the $\mathrm{C}=\mathrm{O}$ double bond. Acrolein can adsorb on this ligand-modified surface with the $\mathrm{C}=\mathrm{O}$ bond pointing towards the Pd surface and forms the propenoxy reaction intermediate resulting from the insertion of a single $\mathrm{H}$ atom into the $\mathrm{C}=\mathrm{O}$ bond followed by the second half-hydrogenation step that leads to propenol formation. A clear correlation between the propenol formation rate and the time evolution of the propenoxy surface intermediate was detected, providing a strong experimental evidence that the propenoxy species is directly involved into the reaction pathway towards propenol. 


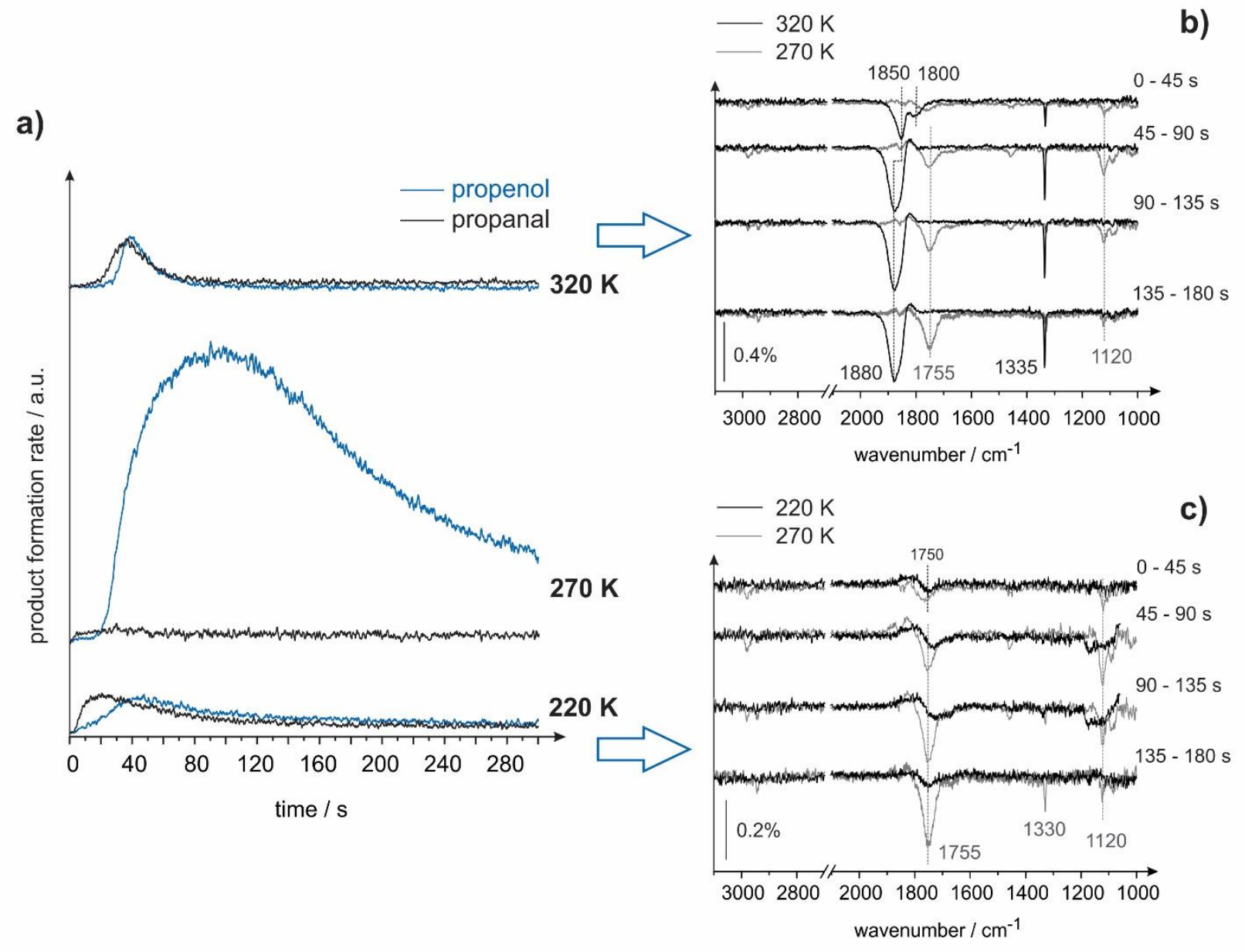

Figure 6. (a) Propenol (blue line) and propenol (black line) formation rates measured over Pd(111) during a continuous exposure to acrolein and $\mathrm{H}_{2}$ at different temperature conditions. (b) The IRAS spectra obtained at $320 \mathrm{~K}$ (black lines) under the reaction conditions during the reaction times indicated on the right. The grey lines show the spectra measured at $270 \mathrm{~K}$ (at otherwise identical reaction conditions), which are plotted for comparison. (c) The IRAS spectra recorded at $220 \mathrm{~K}$ (black lines) on the surface turning over during the reaction times indicated in the right. The grey lines shows the spectra measured at $270 \mathrm{~K}$, which are plotted for comparison (after $\left[{ }^{14}\right]$ ). 
Hydrogenation of acrolein over Pd nanoparticles $/ \mathrm{Fe}_{3} \mathrm{O}_{4} / \mathrm{Pt}(111)$

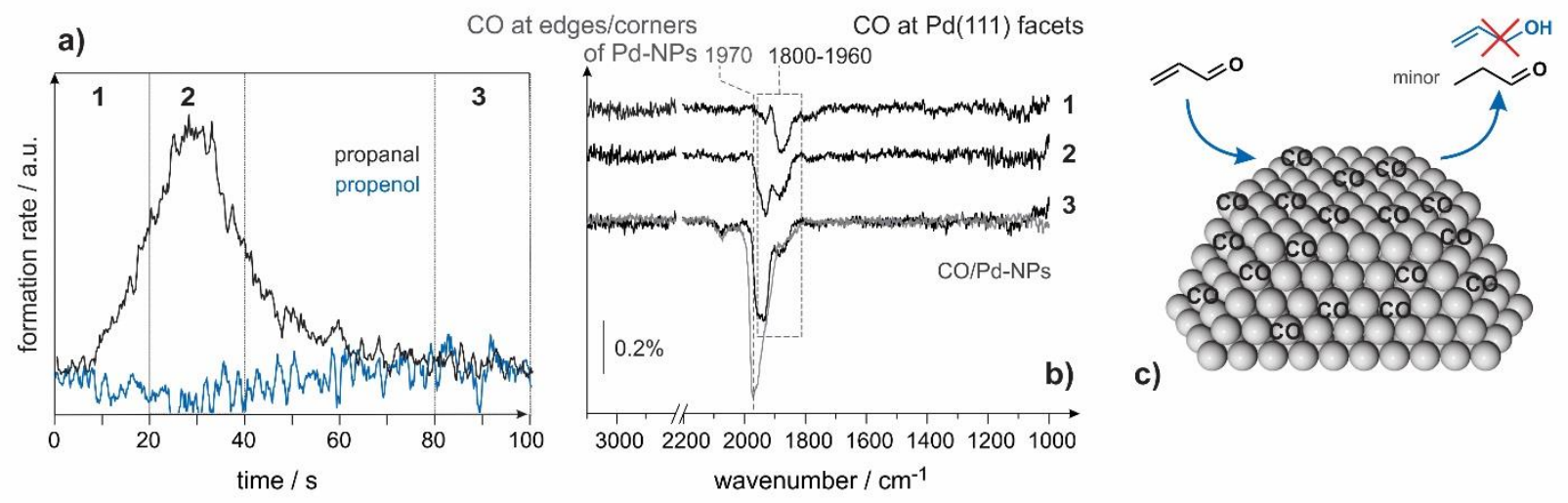

Figure 7. (a) Propanal (black line) and propenol (blue line) formation rates measured in the gas phase over $12 \mathrm{~nm}$-sized $\mathrm{Pd} \mathrm{NPs}$ supported on $\mathrm{Fe}_{3} \mathrm{O}_{4} / \mathrm{Pt}(111)$ at $270 \mathrm{~K}$ and (b) infrared spectra simultaneously recorded at this surface (black lines). The spectra $1-3$ are related to the reaction time regions $1-3$ indicated in (a). The grey spectrum in (b) corresponds to $\mathrm{CO}$ molecules adsorbed on pristine Pd nanoparticles of the same size (after [ $\left.{ }^{14}\right]$ ); (c) Suggested model of the surface reaction on supported Pd nanoparticles: acrolein readily decarbonylates at the edges and other lowcoordinated sites of the nanoparticles forming $\mathrm{CO}$ molecules and some strongly dehydrogenated $\mathrm{CH}_{\mathrm{x}}$ carbonaceous deposits. While the latter species preferentially occupy the edge sites, $\mathrm{CO}$ diffuses to terraces thus preventing formation of the oxopropyl layer on the (111) facets, which is crucial for selective hydrogenation of the carbonyl group. As a result, no propenol formation can be observed and only minor amounts of the undesired product propanal are formed. 
(a)

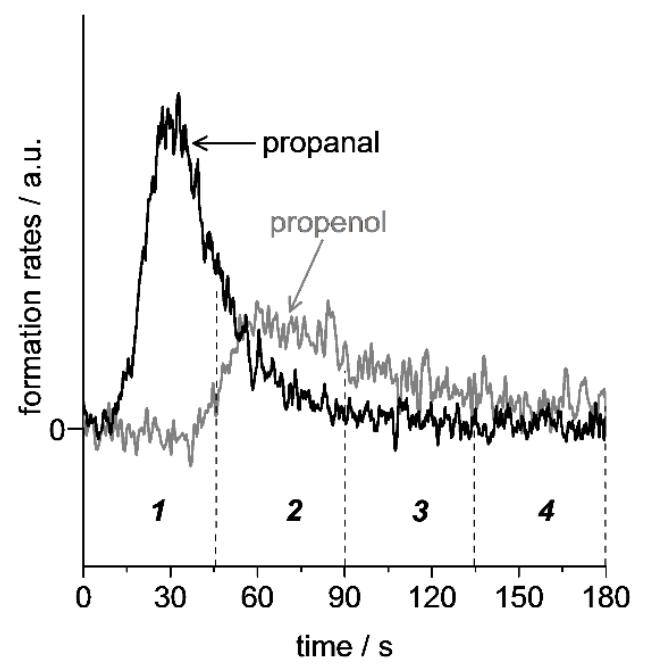

(b)

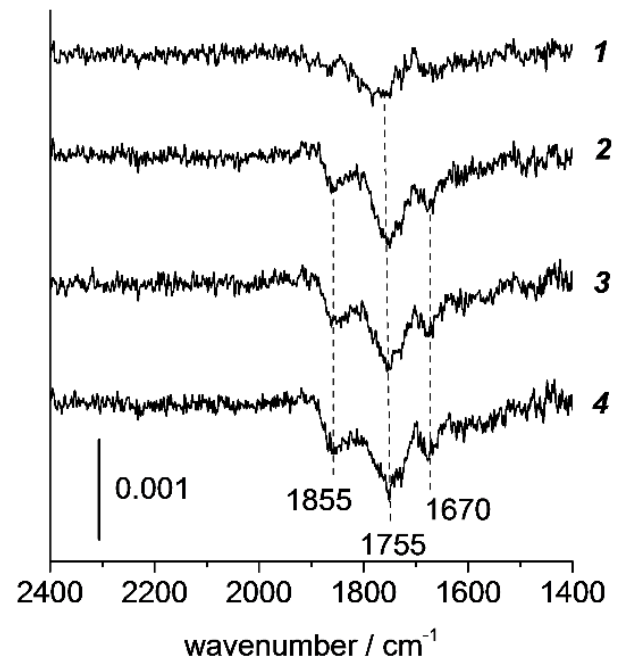

Figure 8. Acrolein hydrogenation over $12 \mathrm{~nm} \mathrm{Pd} / \mathrm{Fe}_{3} \mathrm{O}_{4}$ at $250 \mathrm{~K}$. (a) propanal (black line) propenol (grey line) formation rates measured in the gas phase. (b) time-resolved IRAS spectra obtained during acrolein hydrogenation. Spectra labeled 1-4 were collected during the regions labeled $1-4$ in (a) (after $\left.\left[{ }^{15}\right]\right)$. 
References

1. Rod, T. H.; Nørskov, J. K., The Surface Science of Enzymes. Surf. Sci. 2002, 500, 678-698.

2. Collman, J. P.; Wang, Z.; Straumanis, A.; Quelquejeu, M.; Rose, E., An Efficient Catalyst for Asymmetric Epoxidation of Terminal Olefins. J. Amer. Chem. Soc. 1999, 121, 460-461.

3. Taylor, M. S.; Jacobsen, E. N., Asymmetric Catalysis by Chiral Hydrogen-Bond Donors. Angew. Chem. Int. Ed. 2006, 45, 1520-1543.

4. Marshall, S. T.; O’Brien, M.; Oetter, B.; Corpuz, A.; Richards, R. M.; Schwartz, D. K.; Medlin, J. W., Controlled Selectivity for Palladium Catalysts Using Self-Assembled Monolayers. Nat Mater 2010, 9, 853858.

5. Meemken, F.; Baiker, A., Recent Progress in Heterogeneous Asymmetric Hydrogenation of $\mathrm{C}=\mathrm{O}$ and $\mathrm{C}=\mathrm{C}$ Bonds on Supported Noble Metal Catalysts. Chem. Rev. 2017, 117, 11522-11569.

6. Gellman, A. J.; Tysoe, W. T.; Zaera, F., Surface Chemistry for Enantioselective Catalysis. Catal. Lett. 2015, 145, 220-232.

7. Gallezot, P.; Richard, D., Selective Hydrogenation of Alpha,Beta-Unsaturated Aldehydes. Catal. Rev.-Sci. Eng. 1998, 40, 81-126.

8. Marshall, S. T.; Medlin, J. W., Surface-Level Mechanistic Studies of Adsorbate-Adsorbate Interactions in Heterogeneous Catalysis by Metals. Surf. Sci. Rep. 2011, 66, 173-184.

9. Mark, A. G.; Forster, M.; Raval, R., Recognition and Ordering at Surfaces: The Importance of Handedness and Footedness. ChemPhysChem 2011, 12, 1474-1480.

10. Ernst, K.-H., Molecular Chirality in Surface Science. Surf. Sci. 2013, 613, 1-5.

11. Sípos, É.; Tungler, A.; Fogassy, G., New Substrates and Modifiers in the Enantioselective Heterogeneous Catalytic Hydrogenation of the C - C Double Bond. J. Mol. Catal. A - Chem. 2004, 216, 171-180.

12. Dostert, K.-H.; O’Brien, C. P.; Ivars-Barceló, F.; Schauermann, S.; Freund, H.-J., Spectators Control Selectivity in Surface Chemistry: Acrolein Partial Hydrogenation over Pd. J. Amer. Chem. Soc. 2015, 137, 13496-13502.

13. Dostert, K.-H.; O'Brien, C. P.; Mirabella, F.; Ivars-Barcelo, F.; Schauermann, S., Adsorption of Acrolein, Propanal, and Allyl Alcohol on Pd(111): A Combined Infrared Reflection-Absorption Spectroscopy and Temperature Programmed Desorption Study. Phys. Chem. Chem. Phys. 2016, 18, 13960-13973.

14. Dostert, K.-H.; O’Brien, C. P.; Mirabella, F.; Ivars-Barceló, F.; Attia, S.; Spadafora, E.; Schauermann, S.; Freund, H.-J., Selective Partial Hydrogenation of Acrolein on Pd: A Mechanistic Study. ACS Catal. 2017, 5523-5533.

15. O'Brien, C. P.; Dostert, K.-H.; Schauermann, S.; Freund, H.-J., Selective Hydrogenation of Acrolein over Pd Model Catalysts: Temperature and Particle-Size Effects. Chemistry - A European Journal 2016, 22, 15856-15863.

16. O'Brien, C. P.; Dostert, K. H.; Hollerer, M.; Stiehler, C.; Calaza, F.; Schauermann, S.;

Shaikhutdinov, S.; Sterrer, M.; Freund, H. J., Supports and Modified Nano-Particles for Designing Model Catalysts. Faraday Discuss. 2016, 188, 309-21.

17. Mäki-Arvela, P.; Hájek, J.; Salmi, T.; Murzin, D. Y., Chemoselective Hydrogenation of Carbonyl Compounds over Heterogeneous Catalysts. Appl. Catal. A - Gen. 2005, 292, 1-49.

18. Claus, P., Selective Hydrogenation of $A, B-$ Unsaturated Aldehydes and Other $C=O$ and $C=C$ Bonds Containing Compounds. Top. Catal. 1998, 5, 51-62.

19. Ponec, V., On the Role of Promoters in Hydrogenations on Metals; A,B-Unsaturated Aldehydes and Ketones. Appl. Catal. A - Gen. 1997, 149, 27-48. 
20. Birchem, T.; Pradier, C. M.; Berthier, Y.; Cordier, G., Hydrogenation of 3-Methyl-Crotonaldehyde on the Pt(553) Stepped Surface: Influence of the Structure and of Preadsorbed Tin. J. Catal. 1996, 161, 68-77.

21. Pradier, C. M.; Birchem, T.; Berthier, Y.; Cordier, G., Hydrogenation of 3-Methyl-Butenal on Pt(110); Comparison with Pt(111). Catal. Lett. 1994, 29, 371-378.

22. Vannice, M. A., The Influence of Msi (Metal-Support Interactions) on Activity and Selectivity in the Hydrogenation of Aldehydes and Ketones. Top. Catal. 1997, 4, 241-248.

23. Englisch, M.; Jentys, A.; Lercher, J. A., Structure Sensitivity of the Hydrogenation of Crotonaldehyde over Pt/Sio2and Pt/Tio2. J. Catal. 1997, 166, 25-35.

24. Kennedy, G.; Baker, L. R.; Somorjai, G. A., Selective Amplification of C?O Bond Hydrogenation on Pt/Tio2: Catalytic Reaction and Sum-Frequency Generation Vibrational Spectroscopy Studies of Crotonaldehyde Hydrogenation. Angew. Chem. Int. Ed. 2014, 53, 3405-3408.

25. Schauermann, S.; Freund, H.-J., Model Approach in Heterogeneous Catalysis: Kinetics and Thermodynamics of Surface Reactions. Accounts of Chemical Research 2015, 48, 2775-2782.

26. Akita, M.; Osaka, N.; Itoh, K., Infra-Red Reflection Absorption Spectroscopic Study on Adsorption Structures of Acrolein on Polycrystalline Gold and Au(111) Surfaces under Ultra-High Vacuum Conditions. Surf. Sci. 1998, 405, 172-181.

27. Fujii, S.; Osaka, N.; Akita, M.; Itoh, K., Infrared Reflection Absorption Spectroscopic Study on the Adsorption Structures of Acrolein on an Evaporated Silver Film. The Journal of Physical Chemistry 1995, 99, 6994-7001.

28. Hamada, Y.; Nishimura, Y.; Tsuboi, M., Infrared Spectrum of Trans-Acrolein. Chemical Physics $1985,100,365-375$.

29. Loffreda, D.; Jugnet, Y.; Delbecq, F.; Bertolini, J. C.; Sautet, P., Coverage Dependent Adsorption of Acrolein on Pt(111) from a Combination of First Principle Theory and Hreels Study. J. Phys. Chem. B 2004, 108, 9085-9093.

30. Colthup, N. B.; Daly, L. H.; Wiberley, S. E., Chapter 9 - Carbonyl Compounds. In Introduction to Infrared and Raman Spectroscopy (Third Edition), Colthup, N. B.; Daly, L. H.; Wiberley, S. E., Eds. Academic Press: San Diego, 1990; pp 289-325.

31. Mecke, B.; Noack, K., Untersuchungen Über Die Beeinflussung Der Frequenz Und Intensität Der $\mathrm{Nc}=\mathrm{O}-$ Und Nc=C-Banden Im I.R.-Spektrum Ungesättigter Ketone Durch Konjugation Und Sterische Hinderung. Spectrochimica Acta 1958, 12, 391-393.

32. Mitchell, W. J.; Xie, J.; Jachimowski, T. A.; Weinberg, W. H., Carbon Monoxide Hydrogenation on the Ru(001) Surface at Low Temperature Using Gas-Phase Atomic Hydrogen: Spectroscopic Evidence for the Carbonyl Insertion Mechanism on a Transition Metal Surface. J. Amer. Chem. Soc. 1995, 117, 26062617.

33. Weldon, M. K.; Friend, C. M., Probing Surface Reaction Mechanisms Using Chemical and Vibrational Methods: Alkyl Oxidation and Reactivity of Alcohols on Transitions Metal Surfaces. Chem. Rev. 1996, 96, 1391-1412.

34. Borasio, M.; Rodríguez de la Fuente, O.; Rupprechter, G.; Freund, H.-J., In Situ Studies of Methanol Decomposition and Oxidation on Pd(111) by Pm-Iras and Xps Spectroscopy. J. Phys. Chem. B 2005, 109, 17791-17794.

35. Haubrich, J.; Loffreda, D.; Delbecq, F.; Sautet, P.; Jugnet, Y.; Krupski, A.; Becker, C.; Wandelt, K., Adsorption and Vibrations of A,B-Unsaturated Aldehydes on Pure Pt and Pt-Sn Alloy (111) Surfaces I.

Prenal. J. Phys. Chem. C 2008, 112, 3701-3718.

36. Schauermann, S.; Hoffmann, J.; Johanek, V.; Hartmann, J.; Libuda, J., Adsorption, Decomposition and Oxidation of Methanol on Alumina Supported Palladium Particles. Phys. Chem. Chem. Phys. 2002, 4, 3909-3918.

37. Sexton, B. A., Methanol Decomposition on Platinum (111). Surf. Sci. 1981, 102, 271-281. 
38. Davis, J. L.; Barteau, M. A., Polymerization and Decarbonylation Reactions of Aldehydes on the Pd(111) Surface. J. Amer. Chem. Soc. 1989, 111, 1782-1792.

39. Colthup, N. B.; Daly, L. H.; Wiberley, S. E., Chapter 7 - Olefin Groups. In Introduction to Infrared and Raman Spectroscopy (Third Edition), Colthup, N. B.; Daly, L. H.; Wiberley, S. E., Eds. Academic Press: San Diego, 1990; pp 247-260.

40. Kliewer, C. J.; Bieri, M.; Somorjai, G. A., Hydrogenation of the A,B-Unsaturated Aldehydes Acrolein, Crotonaldehyde, and Prenal over Pt Single Crystals: A Kinetic and Sum-Frequency Generation Vibrational Spectroscopy Study. J. Amer. Chem. Soc. 2009, 131, 9958-9966.

41. King, D. A.; Wells, M. G., Reaction Mechanism in Chemisorption Kinetics: Nitrogen on the $\{100\}$ Plane of Tungsten, 1974; Vol. 339, p 245-269.

42. Hill, J. M.; Shen, J.; Watwe, R. M.; Dumesic, J. A., Microcalorimetric, Infrared Spectroscopic, and Dft Studies of Ethylene Adsorption on Pd and Pd/Sn Catalysts. Langmuir 2000, 16, 2213-2219.

43. Mohsin, S. B.; Trenary, M.; Robota, H. J., Kinetics of Ethylidyne Formation on Pt(111) from TimeDependent Infrared Spectroscopy. Chemical Physics Letters 1989, 154, 511-515.

44. Brown, N. F.; Barteau, M. A., Reactions of Unsaturated Oxygenates on Rhodium(111) as Probes of Multiple Coordination of Adsorbates. J. Amer. Chem. Soc. 1992, 114, 4258-4265.

45. de Jesús, J. C.; Zaera, F., Adsorption and Thermal Chemistry of Acrolein and Crotonaldehyde on Pt(111) Surfaces. Surf. Sci. 1999, 430, 99-115.

46. de Jesús, J. C.; Zaera, F., Double-Bond Activation in Unsaturated Aldehydes: Conversion of Acrolein to Propene and Ketene on Pt(111) Surfaces. J. Mol. Catal. A - Chem. 1999, 138, 237-240.

47. Davis, J. L.; Barteau, M. A., Vinyl Substituent Effects on the Reactions of Higher Oxygenates on Pd(111). J. Mol. Catal. 1992, 77, 109-124.

48. Haubrich, J.; Loffreda, D.; Delbecq, F.; Sautet, P.; Jugnet, Y.; Krupski, A.; Becker, C.; Wandelt, K., Mechanistic and Spectroscopic Identification of Initial Reaction Intermediates for Prenal Decomposition on a Platinum Model Catalyst. Phys. Chem. Chem. Phys. 2011, 13, 6000-6009.

49. Hollins, P.; Pritchard, J., Infrared Studies of Chemisorbed Layers on Single-Crystals. Prog. Surf. Sci. 1985, 19, 275-350.

50. Hoffmann, F. M., Infrared Reflection-Absorption Spectroscopy of Adsorbed Molecules. Surf. Sci. Rep. 1983, 3, 107-192.

51. Morkel, M.; Unterhalt, H.; Salmeron, M.; Rupprechter, G.; Freund, H.-J., Sfg Spectroscopy from 10-8 to 1000 Mbar: Less-Ordered Co Structures and Coadsorption on Pd(1 11 1). Surf. Sci. 2003, 532-535, 103-107.

52. Unterhalt, H.; Rupprechter, G.; Freund, H.-J., Vibrational Sum Frequency Spectroscopy on $\mathrm{Pd}(111)$ and Supported Pd Nanoparticles: Co Adsorption from Ultrahigh Vacuum to Atmospheric Pressuret. The Journal of Physical Chemistry B 2002, 106, 356-367.

53. Bertarione, S.; Scarano, D.; Zecchina, A.; Johanek, V.; Hoffmann, J.; Schauermann, S.; Frank, M. M.; Libuda, J.; Rupprechter, G.; Freund, H. J., Surface Reactivity of Pd Nanoparticles Supported on Polycrystalline Substrates as Compared to Thin Film Model Catalysts: Infrared Study of Co Adsorption. J. Phys. Chem. B 2004, 108, 3603-3613.

54. Xu, X. P.; Goodman, D. W., An Infrared and Kinetic-Study of Co Oxidation on Model SilicaSupported Palladium Catalysts from 10-9 to 15-Torr. J. Phys. Chem. 1993, 97, 7711-7718.

55. Goyhenex, C.; Croci, M.; Claeys, C.; Henry, C. R., Ftir Studies of the Adsorption of Co on Supported Metallic Clusters Pdmgo(100). Surf. Sci. 1996, 352-354, 475-479.

56. Francis, S. A.; Ellison, A. H., Infrared Spectra of Monolayers on Metal Mirrors. Journal of the Optical Society of America 1959, 49, 131-138.

57. Wolter, K.; Seiferth, O.; Kuhlenbeck, H.; Bäumer, M.; Freund, H. J., Infrared Spectroscopic Investigation of Co Adsorbed on Pd Aggregates Deposited on an Alumina Model Support. Surf. Sci. 1998, 399, 190-198. 
58. Schalow, T.; Brandt, B.; Starr, D. E.; Laurin, M.; Schauermann, S.; Shaikhutdinov, S. K.; Libuda, J.; Freund, H.-J., Oxygen-Induced Restructuring of a Pd/Fe3o4 Model Catalyst. Catal. Lett. 2006, 107, 189196.

59. Yudanov, I. V., et al., Co Adsorption on Pd Nanoparticles: Density Functional and Vibrational Spectroscopy Studies. J. Phys. Chem. B 2002, 107, 255-264.

60. Schauermann, S.; Hoffmann, J.; Johánek, V.; Hartmann, J.; Libuda, J.; Freund, H.-J., Catalytic Activity and Poisoning of Specific Sites on Supported Metal Nanoparticles. Angew. Chem. Int. Ed. 2002, $41,2532-2535$.

61. Sonstrom, P.; Baumer, M., Supported Colloidal Nanoparticles in Heterogeneous Gas Phase Catalysis: On the Way to Tailored Catalysts. Phys. Chem. Chem. Phys. 2011, 13, 19270-19284.

62. Schrader, I.; Neumann, S.; Šulce, A.; Schmidt, F.; Azov, V.; Kunz, S., Asymmetric Heterogeneous Catalysis: Transfer of Molecular Principles to Nanoparticles by Ligand Functionalization. ACS Catal. 2017, 7, 3979-3987.

63. Kunz, S., Supported, Ligand-Functionalized Nanoparticles: An Attempt to Rationalize the Application and Potential of Ligands in Heterogeneous Catalysis. Top. Catal. 2016, 59, 1671-1685.

64. Rodríguez-García, L.; Hungerbühler, K.; Baiker, A.; Meemken, F., The Critical Role of Tilted Cinchona Surface Species for Enantioselective Hydrogenation. ACS Catal. 2017, 7, 3799-3809.

65. Lien, C.-H.; Medlin, J. W., Control of Pd Catalyst Selectivity with Mixed Thiolate Monolayers. J. Catal. 2016, 339, 38-46.

66. Pang, S. H.; Medlin, J. W., Controlling Catalytic Selectivity Via Adsorbate Orientation on the Surface: From Furfural Deoxygenation to Reactions of Epoxides. J. Phys. Chem. Lett. 2015, 6, 1348-1356. 67. Hutchings, G. J.; King, F.; Okoye, I. P.; Padley, M. B.; Rochester, C. H., Selectivity Enhancement in the Hydrogenation of A, B-Unsaturated Aldehydes and Ketones Using Thiophene-Modified Catalysts. J. Catal. 1994, 148, 453-463.

68. Chiu, M. E.; Kyriakou, G.; Williams, F. J.; Watson, D. J.; Tikhov, M. S.; Lambert, R. M., Sulfur, Normally a Poison, Strongly Promotes Chemoselective Catalytic Hydrogenation: Stereochemistry and Reactivity of Crotonaldehyde on Clean and S-Modified Cu(111). Chemical Communications 2006, 12831285.

69. Sheldon, R. A.; van Bekkum, H., Catalytic Hydrogenation and Dehydrogenation. In Fine Chemicals through Heterogeneous Catalysis, Wiley-VCH Verlag GmbH: 2007; pp 351-471.

70. Nakamura, Y., Asymmetrische Synteese. lii. Versuch Zur Darstellung Eines Optisch-Aktiven Amins Durch Die Reduktion Des Ketoxims Beim Vorhandensein Von Optisch-Aktiver Säure. Bull. Chem. Soc. Jpn. 1941, 16, 367-370.

71. Mallat, T.; Orglmeister, E.; Baiker, A., Asymmetric Catalysis at Chiral Metal Surfaces. Chem. Rev. 2007, 107, 4863-4890.

72. Peter, M.; Flores Camacho, J. M.; Adamovski, S.; Ono, L. K.; Dostert, K.-H.; O'Brien, C. P.; Roldan Cuenya, B.; Schauermann, S.; Freund, H.-J., Trends in the Binding Strength of Surface Species on Nanoparticles: How Does the Adsorption Energy Scale with the Particle Size? Angew. Chem. Int. Ed.

2013, 52, 5175-5179. 